
INDÚSTRIA DE SORVETES APÓS APLICAÇÃO DE FLOCULANTES

\title{
PHYSICAL AND CHEMICAL CHARACTERIZATION OF INDUSTRIAL EFFLUENTS OF SORVETES AFTER APPLICATION OF FLOCULANTES
}

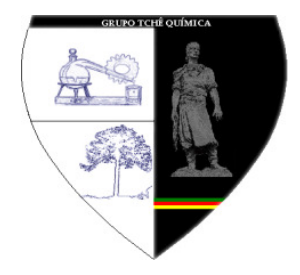

\author{
NIELAND, Maitê Lampert; DALLAZEN, Maria Cristina; UEBEL, Alana; MÜLLER, Maíra \\ Post; COLLING, Marcelo; FREITAS, Elisete Maria de; ETHUR, Eduardo Miranda; \\ HOEHNE, Lucélia*
}

\author{
Centro Universitário - UNIVATES, Av. Avelino Talini, 171 - Universitário, Lajeado - RS, 95914-014 \\ (fone: (51) 3714-7000) \\ *Lucélia Hoehne \\ e-mail: luceliah@univates.br
}

Received 05 July 2017; received in revised form 15 November 2017; accepted 20 December 2017

\section{RESUMO}

A indústria de laticínios tem um papel de grande importância, tanto econômica quanto social no Brasil. Todavia, essa gera um significativo volume de efluente que apresenta elevada carga orgânica. Por conta disso, é necessário um tratamento adequado para o efluente gerado, tentando minimizar ao máximo os impactos ambientais do seu descarte. Uma das alternativas para deixar esses resíduos de acordo com as normas ambientais é o uso de floculantes e coagulantes capazes de neutralizar as cargas elétricas fazendo com que as partículas se unam facilitando o processo de separação. Este trabalho tem como objetivo analisar a eficiência de floculantes para o tratamento de efluente de uma empresa do ramo lácteo localizada na região central do estado do Rio Grande Do Sul no Vale do Taquari. Os floculantes utilizados foram o Aquafloc e Aquaflot. Para isso, foram testados os parâmetros de Óleos e Graxas, Sólidos Sedimentáveis e Demanda Química de Oxigênio (DQO). Como resultados, ambos demonstraram resultados semelhantes e eficiência na redução dos parâmetros analisados após o tratamento. Entretanto, dos parâmetros analisados Aquaflot mostrou-se mais eficiente para remoção de DQO.

Palavras-chave: Coagulante. Óleos e graxas. Demanda Química de oxigênio. Sólidos sedimentáveis.

\section{ABSTRACT}

The dairy industry plays a major role both economically and socially in Brazil. However, it generates a significant volume of effluent that presents high organic load. Because of this, a proper treatment is required for the generated effluent, trying to minimize the environmental impacts of its disposal. One of the alternatives to make these wastes in accordance to the environmental standards is the use of flocculants and coagulants that are capable of neutralizing the negative charges, causing the particles to come together to facilitate the separation process. This study aims to analyze the efficiency of flocculants for the treatment of effluent from a dairy company located in the central region of the state of Rio Grande do Sul, in the Taquari Valley. The flocculants used were Aquafloc and Aquaflot. For this, the parameters of Oils and Greases, Sedimentable Solids and Chemical Oxygen Demand (COD) were tested. Similar results were obtanied with both flocculants. However, from the analyzed parameters, Aquafloc proved to be more efficient for removal of COD.

Keywords: Coagulant. Oils and Greases. Chemical Oxygen Demand. Sedimentable Solids. 


\section{INTRODUÇÃO}

A indústria de alimentos sempre desempenhou um papel fundamental na economia brasileira, essa é uma das mais antigas estruturas econômicas existentes no País, contribuindo com quase $10 \%$ do Produto Interno Bruto (PIB). Dentre os diversos tipos de indústria dispostos neste setor, o de laticínios se encontra entre os quatro principais no Brasil, perdendo apenas para o setor de derivados da carne, de beneficiamento de café, chá e cereais e de açúcares. A estimativa é de que a participação dos lácteos no faturamento da área alimentar se aproxime de 10\% (Carvalho, 2010).

As empresas lácteas nacionais se mostram cada vez mais fortes, e desenvolvem um papel muito importante em questões tanto econômicas quanto sociais. Todavia, seus efluentes se não tiverem um tratamento adequado, contribuem significativamente com a poluição hídrica. Esses danos são dificilmente reversíveis pois, tem uma alta carga orgânica constituída por elevadas concentrações de Demanda Química de Oxigênio (DQO), Demanda Bioquímica de Oxigênio $\left(\mathrm{DBO}_{5}\right)$, Óleos e Graxas, Nitrogênio, Fósforo, entre outros. Para reduzir os efeitos dos poluentes no setor industrial, técnicas de tratamento têm sido aperfeiçoadas e novos métodos estão sendo testados e estudados para minimizar o impacto ambiental dos resíduos gerados.

A grande degradação do meio ambiente tem gerado preocupações de ordem global, o assunto começou a se tornar comum em pautas sociais, o que fez com que este ganhasse grande repercussão causando a divulgação e conscientização de problemas ambientais. Com isso, essa problemática vem sendo refletida e abordada em leis que cobram das empresas o tratamento adequado dos seus efluentes e resíduos, os quais devem estar dentro dos parâmetros nacionais, estaduais e regionais antes de serem descartados, de forma a manter a preservação dos mananciais aquáticos, o equilíbrio da fauna e da flora, evitando possíveis impactos ambientais.

\section{DESENVOLVIMENTO}

A DQO é um parâmetro utilizado como indicador do conteúdo de matéria orgânica em águas residuais, inclusive no monitoramento de estação de tratamento de efluentes líquidos (Aquino et al., 2006).

PERIÓDICO TCHÊ QUÍMICA • www.periodico.tchequimica.com • Vol. 15 N. 29.

- ISSN 1806-0374 (impresso) • ISSN 1806-9827 (CD-ROM) • ISSN 2179-0302 (meio eletrônico)

(C) 2018. Porto Alegre, RS. Brasil
Os Óleos e Graxas tem como principal característica a baixa solubilidade na água. Embora esta característica facilita o processo de separação por flotação, decorrem problemas relacionados ao transporte, por tubulações, dos despejos, sua disposição em água e a degradação nas unidades de tratamento biológico. Isso causa problemas visuais e ambientais por conta da sua acumulação em ambientes com água, assim como praias e margens de rios. Nos tratamentos de efluentes de empresas alimentícias, em especial, indústrias de laticínios, os efluentes possuem Óleos e Graxas em concentrações consideradas altas, sendo necessário o uso de floculantes adequados para eficiente remoção (SABESP, 1997).

Os Sólidos Sedimentáveis são todas as substâncias que existem em um litro da amostra, que sedimentam pela força da gravidade. Sua importância está relacionada diretamente com análises da eficiência de tratamentos de água ou efluente. Quando a intenção é quantificá-los, um dos processos com mais eficiência é a determinação destes através de técnicas normatizadas (SABESP, 1999).

Os coagulantes neutralizam as cargas elétricas das partículas, o que possibilita que as mesmas se unam, formando assim flocos que normalmente flotam ou sedimentam (Matos et al., 2007). Nos casos de efluentes emulsionados, os floculantes/coagulantes desestabilizam o estado coloidal da emulsão, neutralizando assim as forças eletrostáticas e/ou as forças de Van der Waals (Carvalho et al., 2008). A coagulação tem duas fases: a primeira seria a mistura, na qual o coagulante ao se misturar com o efluente, geralmente por um processo rápido, ou seja, por meio de violenta agitação; e a floculação, que seria a agitação do efluente em uma lenta velocidade por um tempo mais longo, o que favorece a junção das partículas muito pequenas e a formação dos colóides (Santos et al., 2009). Os produtos químicos normalmente utilizados como coagulantes/floculantes são a base de sais de ferro e de alumínio, polieletrólitos, além destes, existem os coagulantes naturais, um exemplo é a semente de Moringa oleífera, uma planta arbórea nativa da Índia. Vários são os fatores que influenciam na coagulação, a maioria deles baseados no tempo de mistura, floculação e controle do $\mathrm{pH}$ do efluente. Em cada efluente, existe ao menos uma zona em 
que o $\mathrm{pH}$ é considerado bom para a aplicação do floculante, nesse limite a floculação ocorre em menor tempo. A coagulação sempre deve ser feita nessa condição adequada de $\mathrm{pH}$, pois, isso garante melhor eficiência do processo. (Santos et al, 2009).

Assim, o uso de floculantes adequados podem reduzir custos com reagentes químicos ou tempo de tratamento. Dessa forma, o presente trabalho tem o intuito de avaliar dois floculantes aplicados na etapa do flotador de uma empresa do ramo lácteo, na tentativa de reduzir os parâmetros de Óleos e Graxas, Sólidos Sedimentáveis e DQO.

A empresa do ramo de laticínios em que o presente trabalho foi aplicado e testado está localizada na região central do estado Rio Grande do Sul, no Vale do Taquari e já possui um sistema de tratamento que é dividido em diversas etapas. Inicialmente, o resíduo diário fica estocado em um tanque de armazenamento, após um volume adequado, este é enviado à estação de tratamento. No primeiro tanque da estação de tratamento (etapa 1), grande parte da gordura do efluente fica emersa, sendo facilmente retirada por um sistema de raspagem no tanque que contém capacidade para $10 \mathrm{~m}^{3}$. Após esta etapa, a parte líquida do efluente é enviada para o flotador (objeto alvo deste estudo, intitulada de etapa 2) que tem a vazão de $1 \mathrm{~m}^{3} / \mathrm{h}$. O flotador contém sistema de agitação em forma de hélice, o qual auxilia na agitação e homogeneização do efluente, nessa etapa o $\mathrm{pH}$ é ajustado para 6,5 e é então adicionado individualmente os coagulantes em estudo. Após determinado tempo, ocorre a formação de flocos que são retirados também com sistema de raspagem. $O$ efluente líquido é então enviado para um tanque anaeróbio de $16 \mathrm{~m}^{3}$ (etapa 3) permanecendo em média 1,5 dias. Após, este é enviado para um tanque aeróbio com as mesmas dimensões que o anterior (etapa 4) seguindo finalmente para um tanque de remanejamento contendo $10 \mathrm{~m}^{3}$ (etapa 5). Esta última etapa alimenta um biofiltro de minhoca que é irrigado com o efluente numa velocidade de $10 \mathrm{~min} / \mathrm{h}$. Após passar pelo biofiltro, se 0 efluente estiver de acordo com os parâmetros do Conselho Estadual do Meio Ambiente (CONSEMA), este, é então lançado no corpo hídrico.

Para o estudo, foram testados os floculantes: Aquaflot e Aquafloc que foram adicionados na proporção de $500 \mathrm{~mL}$ para um volume de $10 \mathrm{~m}^{3}$ de efluente, diretamente no tanque flotador em pH 6,5, mantendo o sistema sob agitação por meia hora. Após a aplicação de cada floculante, as amostras foram coletadas e analisadas conforme metodologias do Standard Methods (APHA, 2012). Os parâmetros analisados foram: Sólidos Sedimentáveis, DQO e Óleos e Graxas.

De acordo com o boletim técnico, os coagulantes têm origem polimérica, ambos catiônicos, porém o acquafloc é um coagulante inorgânico enquanto o acquaflot é orgânico. Sua composição facilita a formação de flocos maiores e mais pesados, tendo como consequência uma melhor decantação. Os coagulantes orgânicos auxiliam na remoção de cor e contaminantes tóxicos presentes no efluente. $O$ produto pode ser utilizado em estações de tratamento de efluentes e em alguns processos industriais específicos. Ele atua na fase de coagulação, onde os constituintes sólidos da suspensão são desestabilizados, formando microflocos.

Todas as análises foram retiradas e preservadas conforme procedimento descrito no Standard Methods que compreende o capítulo 160 - Collection and Preservation of Samples (APHA, 2012). Para a análise de Sólidos Sedimentáveis foi utilizada a metodologia 2540-F - Settable Solids (APHA, 2012), em que um litro das amostras foi homogeneizado e transferido para um cone de Imhoff, a amostra permaneceu em repouso por 45 minutos, após, o cone foi girado em 360 permanecendo em repouso por mais $15 \mathrm{~min}$, totalizando uma hora. O resultado dessa análise em $\mathrm{mL} / \mathrm{L}$ é obtido pela leitura dos sedimentos pela escala graduada do cone de Imhoff.

A DQO foi quantificada seguindo 0 método 5220-C - Closed Reflux, Titrimetric Method (APHA, 2012). Em que foi colocado em um tubo de ensaio $1,5 \mathrm{~mL}$ de dicromato de potássio, $2,5 \mathrm{~mL}$ da amostra e $3,5 \mathrm{~mL}$ de ácido sulfúrico com sulfato de prata. Após o preparo da amostra os tubos foram fechados com cuidado, a amostra homogeneizada e submetida à digestão por $2 \mathrm{~h}$ a $105^{\circ} \mathrm{C}$ em bloco digestor, com exceção dos brancos não digeridos, que foram titulados com os demais para correção da molaridade do sulfato ferroso amoniacal (FAS). Após arrefecimento, as amostras foram cuidadosamente transferidas para erlenmeyers de $125 \mathrm{~mL}$, os tubos digestores foram enxaguados com pequenas 
porções de água destilada a fim de evitar a perda da amostra, estas, foram tituladas com solução de FAS, 0,25 M utilizando 3 gotas de solução de ferroin como indicador. O ponto de viragem se dá pela passagem da cor verdemusgo para a coloração marrom alaranjado. Pela elevada carga orgânica as amostras estudadas foram submetidas a uma diluição de 50x para a quantificação da DQO.

Cálculo da DQO (Fórmula 1):

$D Q O\left(m g O_{2} / L\right)=\frac{\left(V_{B D}-V_{A}\right) \times M_{E d S} \times 8000}{2,5(m L \text { de amostra })}$

\section{Figura 1. Fórmula para cálculo de $D Q O$}

$\mathrm{V}_{\mathrm{BD}}=\mathrm{mL}$ de FAS utilizado para titular o branco digerido;

$\mathrm{V}_{\mathrm{A}}=\mathrm{mL}$ de $\mathrm{FAS}$ utilizado para titular a amostra;

$\mathrm{M}_{\mathrm{FAS}}=$ Molaridade real do FAS.

Nota: No caso de diluição da amostra, considerar no cálculo.

A análise de Óleos e Graxas foi realizada por gravimetria seguindo o método 5520-D - Soxhlet Extraction Method (APHA, 2012). Primeiramente, os copos de lipídeos foram secos a $105^{\circ} \mathrm{C}$ em estufa por $2 \mathrm{~h}$, acondicionados em dessecador até temperatura ambiente e pesados em balança analítica. Foi filtrado uma quantidade adequada de amostra, previamente homogeneizada com o auxílio de um Kitassato com capacidade de $1 \mathrm{~L}$ acoplado a um funil de Bückner e este a uma linha de vácuo. A filtração foi realizada com papel-filtro qualitativo que, após a passagem da amostra, foi lavado com água destilada para eliminar quaisquer resquícios de ácido sulfúrico a fim de evitar a degradação da celulose, o papel-filtro foi acondicionado em um cartucho de celulose, estes, foram secos em estufa por $30 \min$ a $105 \mathrm{C}$, após a secagem, os cartuchos foram acoplados ao sistema de Soxhlet para a extração com solvente (Hexano) seguindo as instruções do fabricante do equipamento. A amostra foi imersa em $70 \mathrm{ml}$ de Hexano, permanecendo por um período de $2 \mathrm{~h}$ após, foi submetida a processo de lavagem por mais $1 \mathrm{~h}$, seguindo a recuperação do solvente por 15 min. Os copos de lipídeos foram secos em estufa a $105^{\circ} \mathrm{C}$ por duas horas e pesados até peso constante.
Cálculo para Óleos e Graxas (Fórmula 2):

Óleos e Graxas $(\mathrm{mg} / \mathrm{L})=\frac{(A-B) \times 1000 \times 1000}{V}$

\section{Figura 2. Fórmula para cálculo de Óleos e Graxas}

Onde:

A = peso do copo após a destilação da amostra, em gramas;

$B=$ peso do copo vazio, em gramas;

$\mathrm{V}=$ volume da amostra

\section{RESULTADOS E DISCUSSÃO}

Segundo normas do Conselho Estadual do Meio Ambiente (CONSEMA), os efluentes líquidos de fontes poluidoras somente podem ser lançados em corpos d'água superficiais, direta ou indiretamente, atendendo aos seguintes padrões de emissão. Para $\mathrm{DBO}_{5}$, DQO e Sólidos Suspensos, conforme faixas de vazão em $\left(\mathrm{m}^{3} / \mathrm{dia}\right)$ sendo que para $\mathrm{DQO}$ variam de $Q<20$ a $10000 \leq Q$, numa concentração compreendida respectivamente entre 400 a 150 $\mathrm{mgO}_{2} / \mathrm{L}$. Para Sólidos Sedimentáveis o limite é $\leq 1,0 \mathrm{mg} / \mathrm{L}$, já para Óleos e Graxas minerais $\leq$ $10 \mathrm{mg} / \mathrm{L}$ (CONSEMA, 2006).

Cabe salientar que com exceção de Sólidos Sedimentáveis, todas os parâmetros foram analisados em triplicata submetidas à análise estatística usando 0 programa estatístico Bioestat, ANOVA, com teste Tukey, com $p<0,05$ de nível de significância.

Considerando as características do efluente bruto antes da etapa do flotador, os resultados foram: $50 \mathrm{~mL} / \mathrm{L}$ para Sólidos Sedimentáveis, $4550 \pm 357 \mathrm{mg} / \mathrm{LO}_{2}$ para $\mathrm{DQO}$ e $127 \pm 24 \mathrm{mg} / \mathrm{L}$ para Óleos e Graxas.

Os resultados do efluente após adição dos floculantes estão mostrados nas Tabelas 1, 2 e 3: 
Tabela 1. Eficiência do tratamento para o parâmetro de Sólidos Sedimentáveis:

\begin{tabular}{c|c|c}
\hline $\begin{array}{c}\text { Nome do } \\
\text { coagulante }\end{array}$ & $\begin{array}{c}\text { Resultados } \\
\text { após flotador } \\
\text { (mg/L) }\end{array}$ & $\begin{array}{c}\text { Percentual de } \\
\text { remoção }\end{array}$ \\
\hline Aquaflot & 0,3 & $99,4 \%$ \\
\hline Aquafloc & $>0,1$ & $99,8 \%$ \\
\hline 0,1 : limite de detecção da técnica.
\end{tabular}

Como pode se observar na Tabela 10 comportamento de ambos os floculantes foi similar, ou seja, ambos mostraram-se muito eficientes para a remoção de Sólidos Sedimentáveis. A pequena variação em percentual entre os mesmos, neste caso, pode ser desconsiderada.

Tabela 2. Eficiência do tratamento para o parâmetro de DQO

\begin{tabular}{c|c|c}
\hline $\begin{array}{c}\text { Nome do } \\
\text { coagulante }\end{array}$ & $\begin{array}{c}\text { Resultados } \\
\text { após flotador } \\
\left(\mathbf{m g O}_{\mathbf{2}} / \mathbf{L}\right)\end{array}$ & $\begin{array}{c}\text { Percentual } \\
\text { de remoção }\end{array}$ \\
\hline Aquaflot & $1959 \pm 89^{\mathrm{b}}$ & $57 \%$ \\
\hline Aquafloc & $2275 \pm 357^{\mathrm{a}}$ & $50 \%$ \\
\hline
\end{tabular}

Letras diferentes na mesma coluna significa diferença significativa $(p<0.05)$.

De acordo com a Tabela 2 o floculante que mostrou maior eficiência em relação a redução de DQO foi Aquaflot com remoção de $57 \%$.

Tabela 3. Eficiência do tratamento para o parâmetro de Óleos e Graxas

\begin{tabular}{c|c|c}
\hline $\begin{array}{c}\text { Nome do } \\
\text { coagulante }\end{array}$ & $\begin{array}{c}\text { Resultados } \\
\text { após flotador } \\
\text { (mg/L) }\end{array}$ & $\begin{array}{c}\text { Percentual } \\
\text { de remoção }\end{array}$ \\
\hline Aquaflot & $2,6 \pm 0,8^{\mathrm{a}}$ & $97,9 \%$ \\
\hline Aquafloc & $4,3 \pm 0,9^{\mathrm{a}}$ & $96,6 \%$ \\
\hline
\end{tabular}

Letras diferentes na mesma coluna significa diferença significativa $(p<0.05)$.

De acordo com os resultados obtidos, os dois floculantes apresentam alta eficiência, pois não houve diferença estatística entre os resultados.

\section{CONCLUSÕES:}

De acordo com os resultados, foi possível verificar que a adição de floculantes na etapa 2 da estação de tratamento foi satisfatória, pois, com o uso de ambos os floculantes houve redução significativa de Óleos e Graxas e de Sólidos Sedimentáveis. Tratando-se dos valores de DQO, o floculante Aquaflot se mostrou mais adequado para o tratamento. No entanto, apesar da eficiência do tratamento se aproximar de $50 \%$, os valores apresentados ainda são considerados elevados para os padrões de lançamento, sendo necessário um processo complementar para a redução da carga orgânica neste caso.

\section{AGRADECIMENTOS}

Ao Conselho Nacional de Desenvolvimento Científico e Tecnológico $\mathrm{CNPq}$, ao Centro Universitário - UNIVATES, à Bidatek e ao Parque Científico e Tecnológico do Vale do Taquari - TECNOVATES que de alguma forma contribuíram para a realização deste estudo.

\section{REFERÊNCIAS:}

1. AMERICAN PUBLIC HEALTH ASSOCIATION (APHA). Standard Methods for the Examination of Water and Wastewater. $22^{\text {th }}$ Edition. Amercian Public Health Association Washington, 2012.

2. AQUINO, D. F. S et al. Considerações Práticas Sobre o Teste de Demanda Química de Oxigênio (DQO) Aplicado a Análises de Efluentes Anaeróbios. Engenharia Sanitária Ambiental. V.11 n. 4 out/dez, 2006.

3. CARVALHO, GLAUCO RODRIGUES. A Indústria de laticínios no Brasil: passado, presente e futuro. EMBRAPA, Circular Técnica no102. Juiz de Fora, Minas Gerais, 2010.

4. CARVALHO, S. H. V.; SOLETTI, J.I.; HENRIQUE, G. L. S.; PINTO, L. F.; SILVA, D. I. S. Estudo de Coagulantes para o tratamento de efluentes oleosos, utilizando flotacão por ar dissolvido, Anais do XVII Congresso Brasileiro de Engenharia Química, Recife - PE, 2008.

5. CARVALHO, MARIA J. H. Uso de Coagulantes Naturais no Processo de Obtenção de Água Potável. Maringá, PR, 2008. 
6. CONSEMA - Conselho Estadual do Meio Ambiente $\mathrm{n}^{0} \mathbf{1 2 8}$. Rio Grande do Sul, 2006. Disponível em: <http://www.sema.rs.gov.br/upload/arqui vos/201611/30155644-resolucao-12806-efluentes.pdf>

7. FEPAM - Fundação Estadual de Proteção Ambiental. Henrique Roessler. Manual da Fepam, 2008.

8. MATOS, A. T.; CABANELLAS, C. F. G.; CECON, P. R.; BRASIL, M. S.; MUDADO, C.S. Efeito da concentração de coagulantes e do $\mathrm{pH}$ da solução na turbidez da água, em recirculação, utilizada no processamento dos frutos do cafeeiro. Engenharia Agrícola, v. 27, n. 2, Jaboticabal, SP, p. 545, 2007.

9. Norma Técnica Interna - Companhia de Saneamento Básico do Estado de São Paulo (SABESP) NTS 004: DQO Demanda Química de Oxigênio. São Paulo, 1997.

10. Norma Técnica Interna - Companhia de Saneamento Básico do Estado de São Paulo (SABESP) NTS 005: Óleos e Graxas. São Paulo, 1997.

11. Norma Técnica Interna - Companhia de Saneamento Básico do Estado de São Paulo (SABESP) NTS 013: Sólidos. São Paulo, 1999.

12. Santos, A. M., Silva, S. R., Carvalho, S. H. V., Soletti, J. I.; Tratamentos de efluentes lácteos através de coagulação química e sedimentação. Uberlândia, Minas Gerais, 2009.

13. Teixeira, C.O.; Efluentes de laticínios, enquadramento legal e a representação dos técnicos e gerentes. Juiz de Fora, Minas Gerais, 2011. 